Research Article

\title{
Process evaluation of maternal health service at outreach sites during health and nutrition day (Mamta day) in urban slums of Western India
}

\author{
Kedar G. Mehta*, Chandresh M. Pandya, Dipak M. Solanki
}

\author{
Department of Community Medicine (PSM), GMERS Medical College \& General Hospital, Gotri, Vadodara, Gujarat, \\ India
}

Received: 29 January 2016

Accepted: 05 March 2016

\author{
*Correspondence: \\ Dr. Kedar Mehta \\ Email: kedar_mehta20@yahoo.co.in
}

Copyright: (C) the author(s), publisher and licensee Medip Academy. This is an open-access article distributed under the terms of the Creative Commons Attribution Non-Commercial License, which permits unrestricted non-commercial use, distribution, and reproduction in any medium, provided the original work is properly cited.

\begin{abstract}
Background: The concept of health and nutrition day (Mamta Divas) evolved under Reproductive \& child health programme to strengthen the outreach maternal and child health services. So the current study was conducted to monitor the antenatal care services provided at outreach sites during Mamta Divas by urban health centers in slum areas of Vadodara in Western India.

Methods: A cross sectional study was conducted to include one randomly selected outreach session from all of the 17 urban primary health centers of Vadodara city from April-2013 to March-2014. 17 session sites were observed for process evaluation of three components of maternal health care viz, availability of 'service providers', 'equipment's and supplies' and 'direct observation of actual service provision' at the site using a structured checklist.

Results: Out of 17 session sites visited, auxillary nurse midwife was present at 14 sites but health supervisors were not present at any site. Most of the equipments and supplies were present at all sites but Iron folic acid tablets were observed at 9 sites only. Antenatal history taking, weighing of the pregnant woman, injection tetanus toxoid was done at all sites but correct blood pressure measurement and hemoglobin estimation was observed at 4 and 3 sites respectively. Abdominal examination was not observed at any site.

Conclusions: Antenatal services like registration of antenatal women, their weighing and providing tetanus toxoid were mainly focused but other services like identification of high risk pregnancy, abdominal examination, blood pressure measurement and hemoglobin estimation needs to be strengthened during Mamta divas.
\end{abstract}

Key words: Mamta divas, Process evaluation, Maternal care, Urban slums

\section{INTRODUCTION}

Maternal health is not only an important component for health sector but it serves as an important indicator for overall development as well. Maternity forms a vulnerable period in the life of a woman. Any developed country cares for her women in this important phase of their lives. The most commonly used indicator for tracking progress in maternal health is maternal mortality ratio. Gujarat stands at 122 maternal deaths per lac live births in this regard which is yet to cross 100 per lac live births. 1

In India, urbanization is also happening at faster rate with its associated problems many of which affect the health sector. There is also a large urban rural difference when it comes to the health services and health indicators. For decades after independence, rural areas have received large focus in service delivery infrastructure. On the flip side, urban areas have been the last to receive such attention. It was believed that the large concentration of 
doctors and health facilities in urban areas would be enough to serve the general and maternal health needs of urban population. It was later realized that the health status indicators of the population of urban slums is worse than that of the rural population. A recent study by Nimbalkar et al in Anand district in Gujarat supports this with findings that the maternal health services utilization is poor in urban slums compared to the rural area. ${ }^{2}$

Integrated Nutrition and Health Project gave the concept of Nutrition and Health Day which has been widely replicated across the nation in various forms like Mamta Abhiyan. Mamta Abhiyan is an approach to strengthen outreach maternal and child health services. It consists of five components: Mamta day (Health and Nutrition Day), Mamta mulakat (postnatal care visit), Mamta sandarbh (referral services), Mamta nodh (record and reports) and Mamta taruni (Adolescent health). ${ }^{3}$

Maternal care services can be divided in three broad stages: ante-natal, intra natal and post natal care. The health services in the city of Vadodara are provided by a network of urban health centres run by the local selfgovernance body. The antenatal care is provided at urban primary health centres as well as through outreach services in the form of Mamta Divas. Mamta divas is the Gujarat version of what is nationally known as Village Health and Nutrition Day. ${ }^{4}$ This is usually done at an Anganwadi centre located within a slum/semi-slum area. For intranatal care, most slum dwellers are dependent on the tertiary care hospitals located in the city and the private hospitals as the urban health centres are yet to start providing intra natal care on 24 by 7 basis. The post natal care is provided through home visits by the paramedical staff of these urban health centres.

The present study was conducted with the objective to monitor the antenatal care services provided at the outreach sites during the health and nutrition day (Mamta divas) by the Urban Health Centres in urban slums of Vadodara city.

\section{METHODS}

This was cross sectional observational study carried out in Vadodara city which is third most populous city in Gujarat and situated in the central part of the state. There are a total of 17 urban primary health centres run by Vadodara Mahanagar Seva Sadan which is urban local self-governance body. Each of these centres caters to the varying number of population in their assigned geographic area. The major beneficiaries of the services provided by these centres are the people residing in slum and semi-slum areas within jurisdiction of respective urban health centre. These Urban health centres organize a health and nutrition day mainly for pregnant women, lactating mothers, children and adolescents once a month in these slum and semi-slum areas. One outreach session site from each urban health centre was randomly selected from micro plan of all 17 urban health centres of
Vadodara city to cover all the urban health centres. Thus we had observed a total of 17 health and nutrition day sessions for this study. The data collection for the study was from April 2013 to March 2014.

The visits were conducted as a part of regional monitoring teamwork for monitoring of the Reproductive and Child health $(\mathrm{RCH})$ program by the faculty of community Medicine department of Medical College in an assigned corporation. Necessary permission was given from the state government to monitor this activity and also they had given necessary instructions to local health authorities for providing support and information.

We have covered three components for the process evaluation viz, the availability of service provider at the session site, availability of equipments and supplies as well as the direct observation of actual service provision at the site. The structured checklist was based on the Guidelines for antenatal care by Government of India, Mamta Abhiyan guidelines prepared by the state of Gujarat as well as Village Health and Nutrition Day guidelines by Government of India. ${ }^{5,6}$

Process evaluation of each health and nutrition day was done by using the structured checklist on the day of actual session at the site. Data collection was done by single observer to avoid any possibility of observer bias. Adequate time was given to monitor each component of antenatal care provided during health and nutrition day. It was ensured that the data collection does not interfere with the on-going services. The staff members were briefed about the nature and purpose of the exercise beforehand and consent was taken from the clients of the outreach session. On site corrective measures were taken as and when required and feedback was given to local staff, medical officer and local health authorities for the improvement in quality of services.

Microsoft Office Excel was used for data entry and analysis. This being a descriptive study it reports actual numbers and proportions in the form of percentages of the study variables. No statistical significance tests were used.

\section{RESULTS}

The study includes findings from the observation of a total of 17 health and nutrition day sessions at the Anganwadi centre under the urban health centres.

All sessions were held as per microplan and due list of beneficiaries as per E-mamta was available at 14 out of 17 sessions. An auxiliary nurse midwife was present at 14 out of 17 sessions. Anganwadi worker and Community link volunteer were present at all sessions. Anganwadi helper was present at 14 out of 17 sessions. The multipurpose male health workers were present at only 3 sessions. The supervisors from health and Integrated Child Development Services scheme as well as other 
members of the health and sanitation committee were not present at any session as shown in Table 1.

\section{Table 1: Availability of service providers at session site $(n=17)$}

\begin{tabular}{|c|c|c|}
\hline Service providers & Number & $\%$ \\
\hline $\begin{array}{l}\text { Auxiliary Nurse Midwife } \\
\text { (ANM) / Female health } \\
\text { worker (FHW) }\end{array}$ & 14 & 82.4 \\
\hline Anganwadi worker (AWW) & 17 & 100.0 \\
\hline Anganwadi Helper (AWH) & 14 & 82.4 \\
\hline $\begin{array}{l}\text { Community Link Volunteer } \\
\text { (ASHA) }\end{array}$ & 17 & 100.0 \\
\hline $\begin{array}{l}\text { Male Multipurpose Health } \\
\text { Worker (MPHW) }\end{array}$ & 3 & 17.6 \\
\hline Supervisor from Health dept. & 0 & 0.0 \\
\hline Supervisor from ICDS dept. & 0 & 0.0 \\
\hline $\begin{array}{l}\text { Member of Health and } \\
\text { Sanitation committee }\end{array}$ & 0 & 0.0 \\
\hline
\end{tabular}

We also enquired about the availability of the essential items for providing the services at Mamta divas. Table 2 provides information regarding availability of items pertaining to maternal health component of the services only. While collecting this information it was decided that if any item is not available in sufficient quantity as per the demand it would be considered not available. Also item that is not functioning would also be considered not available.

Table 2: Availability of essential items (n=17)

\begin{tabular}{|lll|}
\hline Item & Number & $\%$ \\
\hline Equipment's \& instruments & & \\
\hline BP Instrument & 6 & 35.3 \\
\hline Stethoscope & 6 & 35.3 \\
\hline Examination table & 0 & 0.0 \\
\hline Inch tape & 4 & 23.5 \\
\hline Weighing scale (adult) & 16 & 94.1 \\
\hline Foetoscope & 0 & 0.0 \\
\hline AD (0.5 ml) Syringes & 17 & 100.0 \\
\hline Functional Hub Cutter & 15 & 88.2 \\
\hline Supplies & & \\
\hline Nutrition supplements from ICDS & 17 & 100.0 \\
\hline Injection TT & 17 & 100.0 \\
\hline IFA Tablets (large) & 9 & 52.9 \\
\hline Calcium tablets & 16 & 94.1 \\
\hline Folic acid tablets & 2 & 11.8 \\
\hline Pregnancy testing kit & 4 & 23.5 \\
\hline Haemoglobin testing kit & 3 & 17.6 \\
\hline Urine testing kit/uristix strips & 1 & 5.9 \\
\hline Blank Mamta Cards & 17 & 100.0 \\
\hline Register 4 and 5 & 12 & 70.6 \\
\hline
\end{tabular}

It can be seen from the table 2, that a weighing scale for adults, injection TT with the Auto Disabled syringe, nutritional supplements, calcium tablets, a functional hub cutter and supply of black mamta cards were available at most of the sessions. Iron \& Folic acid (IFA) tablets and plain folic acid tablets was available only at 9 and 2 session sites respectively. Availability of the rest of the items was varying at different session sites.

Table 3: Observation of service delivery $(n=17)$

\begin{tabular}{|lll|}
\hline Service & Number & $\%$ \\
\hline $\begin{array}{l}\text { Registration of woman and } \\
\text { history taking }\end{array}$ & 16 & 93.8 \\
\hline $\begin{array}{l}\text { Privacy ensured during } \\
\text { examination }\end{array}$ & 0 & 0.0 \\
\hline $\begin{array}{l}\text { Blood pressure measured } \\
\text { and recorded properly }\end{array}$ & 4 & 23.5 \\
\hline $\begin{array}{l}\text { Pregnant woman weighed } \\
\text { and the weight recorded } \\
\text { properly }\end{array}$ & 16 & 94.1 \\
\hline $\begin{array}{l}\text { Abdominal palpation } \\
\text { performed }\end{array}$ & 0 & 0.0 \\
\hline $\begin{array}{l}\text { Auscultation of foetal heart } \\
\text { sounds }\end{array}$ & 0 & 0.0 \\
\hline $\begin{array}{l}\text { Injection tetanus toxoid } \\
\text { provided }\end{array}$ & 17 & 100.0 \\
\hline IFA tablets provided & 9 & 52.9 \\
\hline $\begin{array}{l}\text { Calcium tablets provided to } \\
\text { the third trimester women }\end{array}$ & 16 & 94.1 \\
\hline $\begin{array}{l}\text { Folic acid tablets provided } \\
\text { to the first trimester women }\end{array}$ & 2 & 11.8 \\
\hline $\begin{array}{l}\text { Hemoglobin estimation of } \\
\text { the pregnant women }\end{array}$ & 3 & 17.6 \\
\hline $\begin{array}{l}\text { Adequate and relevant } \\
\text { counseling provided to } \\
\text { client }\end{array}$ & 14 & 62.4 \\
\hline $\begin{array}{l}\text { Counseling regarding } \\
\text { nutrition to the pregnant } \\
\text { women }\end{array}$ & 12 & 11.6 \\
\hline $\begin{array}{l}\text { Identification of High risk } \\
\text { antenatal women }\end{array}$ & 4 & \\
\hline $\begin{array}{l}\text { Referral to Urban health } \\
\text { centers }\end{array}$ & 16.5 \\
\hline
\end{tabular}

As can be seen from table 3, history taking specially from the women coming for first visit in first trimester; weighing of the pregnant woman; provision calcium tablets was done at most of the sessions. But provision of Iron \& Folic acid (IFA) tablets and plain folic acid tablets was observed at 9 and 2 session sites respectively. The abdominal examination of the woman by abdominal palpation including auscultation of fetal heart sounds were not performed at any session site. Also no separate curtains or arrangements were available for ensuring privacy of women being examined at any of the session sites. Correct blood pressure measurement and record was done at only 4 out of 17 sessions. 


\section{DISCUSSION}

The health and nutrition day popularly known as Mamta Divas in Gujarat focuses on pregnant women, lactating mothers, children under 5 years and adolescent girls as target groups. This paper has focused on the process assessment of the maternal health component at the health and nutrition day sessions.

The services for the maternal health component mainly cover antenatal care during the session. It covers a range of services for antenatal care of the pregnant woman. The Mamta divas guidelines by the government of Gujarat have identified the specific stations and the work distribution during mamta divas for various staff members. ${ }^{5-6}$ The staff members from the department of health are the ANM, Female Health Supervisor and the Community Link Volunteer. The staff members from the Integrated Child Health Services scheme run under ministry of women and child development are the anganwadi worker and Anganwadi helper. The members of the health and sanitation committee (later renamed as health, sanitation and nutrition committee) many of who are local community members apart from the above mentioned members from Health and ICDs are also expected at the mamta divas session. In this study we found that ANM and Anganwadi staff was available at majority sessions. The study by Kotecha et al in another city of Gujarat also found adequate availability of the health and ICDS staff. ${ }^{7}$ The presence of the male multipurpose health workers was available at very few sessions. The supervisors from the health and ICDS visit the mamta divas sessions in their respective areas as per their schedules such that every session sites gets a visit by the supervisor at least once every quarter. Yet we observed that none of the session observed by us had presence of the supervisor either from health or ICDS side. The absence of the other members of the health and sanitation committee was also noted. Supervision is one of the important components to improve the maternal health care. Involvement of Medical officers of Urban Health centres in supervision of Health and Nutrition day is very much needed to improve quality of services.

The different services offered to antenatal woman starts from early registration of pregnant woman and history taking. This is especially important for those women coming for the first antenatal visit in the first trimester. This was found to be satisfactory in most of the sessions in this study. Saxena et al observed that this was the only service which was most commonly available at the sessions studied by them in Uttarakhand state. ${ }^{8}$

An important issue is that the Mamta divas session is held at Anganwadi centre which was primarily built keeping in focus the needs for services to be provided to children under 6 years of age under ICDS scheme. The infrastructure including the room size and other furniture facilities are grossly inadequate for conducting the physical check-up of the antenatal woman. Hence, the abdominal examination of the antenatal women was not conducted at any sessions. Even the blood pressure measurement equipment was available at only 6 sessions out of which only 4 were doing accurate blood pressure measurement and recording. The abdominal palpation of the woman, taking abdominal girth, auscultation of fetal heart sounds and antenatal breast examination of the woman for prevention of possible breast feeding problems was also not being done. Kotecha et al also observed similar findings regarding blood pressure measurement. ${ }^{7}$ Saxena $\mathrm{V}$ et al in their study on Village Health and Nutrition Day services in the state of Uttarakhand also observed that blood pressure measurement was done at only half of the sites and abdominal examination was done at only two of the 23 sites. $^{8}$

With regard to the investigations available at the session, only 3 sessions had the hemoglobin testing kits available which is similar to the finding by Kotecha et al and Saxena et al. ${ }^{7-8}$ Most of the urban health centres had a practice of calling the antenatal women to the centre itself for getting the hemoglobin and HIV test done. Pregnancy test kits were also available at only 4 out of 17 sessions whereas, urine testing kit was available at only 1 session. It was also interesting to note that many of these antenatal women were getting abdominal ultrasonography done from government or private hospitals which mean that they were also receiving consultations from specialist doctors elsewhere. Among the services tetanus toxoid was available to antenatal women at all sessions. Saxena et al also reported to observe around $80 \%$ of the sessions giving tetanus toxoid. ${ }^{8}$ Iron and folic acid tablets were available and distributed at only 9 sessions. Yet the cross checking with antenatal women present during the session confirmed that they had earlier received the tablets. Thus unavailability of IFA tablets was a temporary but important issue. However, Kotecha et al reports that majority of the sessions in their study were offering IFA tablets without any short supply. ${ }^{7}$ Supply and distribution of calcium tablets was satisfactory. However the folic acid supplementation was not uniform as availability and distribution was observed at only 2 sessions. Kotecha et al also showed that only half of the sessions in their study gave folic acid tablets to the eligible pregnant women.

Counselling of the antenatal woman forms an important component of the services. The counselling offered at the sessions mainly by the ANM covered general dietary advice, reminder on follow up visits, importance of institutional deliveries and preparation of birth micro plan as well as information about the benefits available through various government schemes. But detailed counselling related to proper antenatal care and nutrition was lacking. Similar finding was also observed by Rajkumari et al in Hyderabad. ${ }^{\text {? }}$

With regard to the record keeping filling up of relevant details in Mamta Card was adequate. 12 sessions had the register no. 4 and 5 which are for maternal and child health services available at session site. These registers 
were updated on daily basis which was a good practice observed. However, identification of high risk pregnant women was done at 4 sites and referral to urban health centres was done at 11 sites. Referral to UHC was not only done because of high risk pregnancy but also for HIV screening and Hemoglobin estimation.

There were some limitations of the study. Health and Nutrition day mainly focuses on the antenatal aspects, so in maternal health care services, we could include only antenatal care in this study. While intra-natal and post natal care were out of the scope of this study. We have covered the essential antenatal care components as per the RCH guidelines.

\section{CONCLUSION}

From the study it was observed that registration of antenatal women, their weighing, providing tetanus toxoid and IFA tablets were the main services focused during the health and nutrition days. The other services like correct blood pressure measurement, haemoglobin estimation, abdominal examination, identification of high risk pregnancy and referral services need to be strengthened. Also infrastructure support is a major issue when the sessions are conducted at outreach sites. A regular supply of some of the essential items like IFA tablets, folic acid tablets, pregnancy testing kits, urine testing kits are also to be ensured.

\section{ACKNOWLEDGEMENT}

We are thankful to Addl. director (FW) Government of Gujarat, Medical Officer of Health VMSS, Medical officers and staff members of all UHTCs for their utmost support in the study.

Funding: Department of Health \& Family Welfare, Govt. of Gujarat

Conflict of interest: None

Ethical Approval: Not required

\section{REFERENCES}

1. Special bulletin on maternal mortality in India 201012. New Delhi: Office of the Registrar General,
India; December2013. Available from: http:// www.censusindia.gov.in/ vital_statistics/ SRS_Bulletins/ MMR_Bulletin-2010-12.pdf.

2. Nimbalkar A, Shukla V, Phatak A, Nimbalkar S. Newborn care practices and health seeking behavior in urban slums and villages of Anand, Gujarat. Indian Pediatr. 2013;50(4):408-10.

3. Government of India, Ministry of Health and Family Welfare, Guide-lines for VHND. Delhi. 2007.

4. Government of Gujarat. MAMTA Abhiyan Guidelines. Gandhinagar, Ministry of Health and Family Welfare, Government of Gujarat. 2006.

5. Government of India. Guidelines for Ante-nata Care and Skilled attendance at Birth by anms and lhvs. New Delhi: Maternal Health Division, Department of Family Welfare, Ministry of Health \& Family Welfare; 2005.

6. Government of India. Monthly Village Health and Nutrition Day-Guidelines for awws/ashas/ anms/pris. New Delhi: Ministry of Health and Family Welfare, Government of India. February 2007; Available from: http://nrhm.gov.in/ images/ pdf/ communitisation/vhnd/vhnd_guidelines.pdf

7. Kotecha I, Singh MP. Process Evaluation of Health and Nutrition Day (Mamta Day) in Urban Slum Areas of Bhavnagar Municipal Corporation. Natioanl Journal of Integrated Research in Medicine. 2012;3(1):111-4.

8. Saxena V, Kumar P, Kumari R, Nath B, Pal R. Availability of Village Health and Nutrition Day services in Uttarakhand, India. J Fam Med Primary Care. 2015;4:251-6.

9. Rajkumari HK, Hira P, Rithuma O, Murthy GV, Ajitha K, Suresh M. Evaluating the Fixed Nutrition and Health Day (FNHD) program in the rural area of Shamirpet, Ranga Reddy District and the urban area of Dabeerpura, Hyderabad District. Nat J Res Com Med. 2012;1:101-5.

Cite this article as: Mehta KG, Pandya CM, Solanki DM. Process evaluation of maternal health service at outreach sites during health and nutrition day (Mamta day) in urban slums of Western India. Int J Community Med Public Health 2016;3:881-5. 